\title{
Constructing an Effective Primary English Learning Model Based on Learning Community
}

\author{
Zhongyu Zhang \\ Modern Educational technological institute of Qujing Normal University, Qujing, Yunnan , China \\ 655000 \\ ydzzy@126.com
}

\begin{abstract}
Keywords: Effectiveness ; Learning model; Learning community; Integrated English teaching and learning method
\end{abstract}

\begin{abstract}
In this paper, a primary English learning model based on learning community was proposed. According to this model, an experiment of English teaching and learning was done in a English training institution. The result illustrate that this model is apparently effective for the primary school students to learn English.
\end{abstract}

\section{Introduction}

English As an academic or a life communication tool is more and more important. The effective English teaching is the hot research topic. In Chinese primary school, English learning course often begins from grade 1 or grade 3 in elementary and secondary school. But in most primary school, the effectiveness of English learning is not so much good. The reasons which effects on the English learning result are complex. For example, the teacher's teaching level, the student numbers of the class, the class time and the teaching methods. According to the survey about the English teaching and learning of primary school, most school set only one or two hours a week for English learning. Many primary school didn't put the English learning in an important place. So almost 90 percent students had not reach the qualified level in their English learning when they graduated from the primary school. In order to improve the effectiveness of the English learning class, some teachers proposed to adopt new educational technology [1]. Some other teachers try to improve the classroom teaching effects by using a new teaching method [2]. Most of the teachers concentrate mainly on the effective English teaching such as the professional knowledge, the teaching methods or the teaching resources [3], but not on the language skill training process and the results for the students learning English. Perhaps this is an important reason for most primary school which can not get the appropriate effectiveness.

In this paper, an effective English learning model based on learning community was proposed. Learning community is one of the current most effective learning models in the world. We have done an experiment to use this model in the English training course for the primary school students. The results illustrate that the training model is beneficial to find the students' problems in their English learning process. Solving these problem can apparently improve the effectiveness of the English learning. Section 1 analyze the key factors which influence the effects of English learning. Section 2 proposed an effective English learning model based on learning community. Section 3 describe the result of the experiment about this model. Section 4 introduce the conclusion and future work.

\section{The factors Analyzing of Primary English Learning Effectiveness}

In order to find an effective English learning model, it is necessary to analyze the factors which affect the English learning result. Firstly, the teacher is a key factor for students to learn English. The professionality is important for English teachers to teach well. Secondly, a textbook as the learning resource must be determined. Then, how the teacher teach the students. Thirdly, there must be a teaching or learning method for teachers to have the class. Fourthly, there must be a reviewing way for students to go over what they have learnt. Generally speaking, the parents is very important 
to supervise the children's English learning. But most of them don't know how to teach their children English. So a network course that match with the textbook was developed. Children can follow the network course to go over the lesson. Fifthly, how to inspect the effectiveness? In traditional teaching process, homework is the main way for teachers to help student to master English. This is also the key ways in English school learning. In most primary school, the homework is so great many that the primary students didn't have much time to attend the out class activity. In aspect of the primary students' English learning, the listening, talking, reading and writing ability is the often standard of English learning. How to develop the listening, talking, reading and writing ability of primary students is the main aim of the teaching and learning research of English learning.

\section{An effective English learning model based on learning community}

According to the discussion above, we try to construct a creative model to reach the goal of effectively listening, talking, reading and writing ability. Nowadays, in the world education, learning community is the very popular way to improve the teaching and learning quality. So we try to use the community ideas to construct the teaching and learning model. The model is expressed in fig. 1. This model emphasize the children is the center of English learning. The Expert, teachers, parents as the important factors are included in this model. In addition to these three factors, society is also included in this model. Here society means the society activity for students to use their English to do some actually service. Why the expert is an important factor? We think that the theories and methods should be the advanced and scientific. The expert can guide the whole research and experiment process of the English teaching and learning. The teachers is the executors of teaching and learning activity. According to the American standards of Qualified Teaching Status (QTS), A qualified teacher must have had a secure knowledge and understanding of a range of teaching, learning and behavior management strategies and know how to use and adapt them, including how to personalize learning and provide opportunities for all learners to achieve their potential[5]. The parents is the supervisor of the children's learning of English.

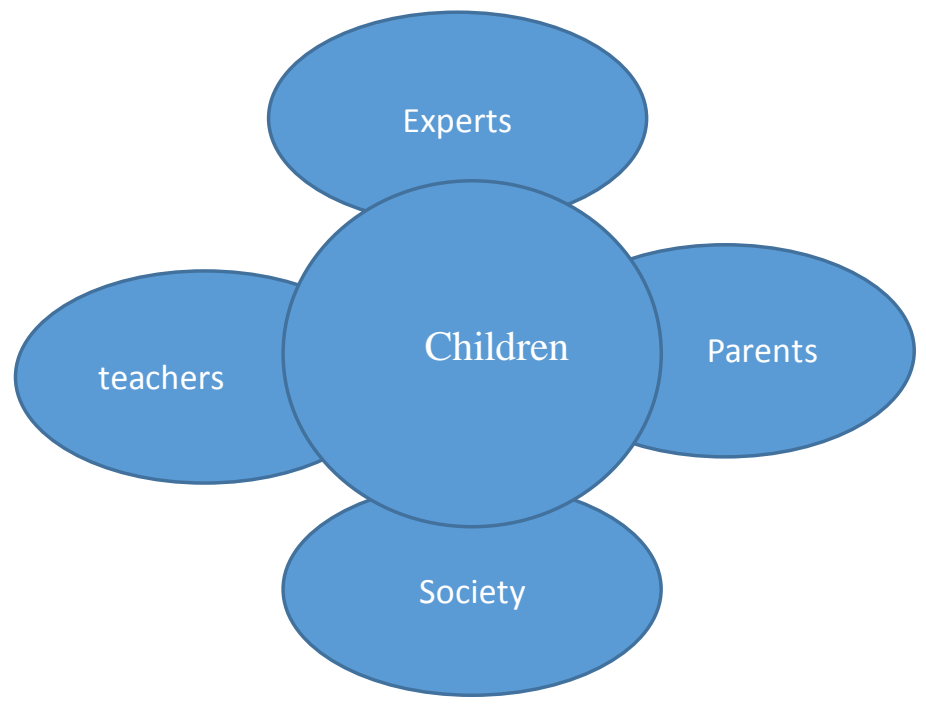

Figure 1. The community model of English learning

\section{Experimental Results of this Community Model}

In order to evaluate the effectiveness of this community model of English learning, an experiment was designed. The treatments are the twenty primary students. The experiment method is the single group pretest and posttest. The pretest information (independent variables) about the treatments before the experiment is listed in table 1 of the following. 
Table 1 The basic information of the treatments

\begin{tabular}{|c|c|c|c|c|}
\hline Group & Age & Grade & Numbers & English level \\
\hline 1 & $7-8$ & $1-2$ & 7 & 0 \\
\hline 2 & $9-11$ & $3-5$ & 13 & 0 \\
\hline
\end{tabular}

Table 2 The pretest of the experimental group

\begin{tabular}{|c|c|c|c|c|c|c|c|c|}
\hline Group & letters & phonetic & pronounce & Words & idioms & sentences & listening & speaking \\
\hline 1 & No & No & No & No & 0 & 0 & No & No \\
\hline 2 & No & No & No & No & 0 & 0 & No & No \\
\hline
\end{tabular}

What operators were done in this experiment for the treatments? According to the proposals of experts, we choose a new method--- Integrated English teaching and learning method to do this experiment. This method is created by the International Integrated English teaching and learning research center led by professor Feng Zenjun of Zhongshang university [4]. The feature of this method is that the main activity is the reading. Listening, talking, writing ability of learner are all developed by the reading. The principle of this method is as Fig. 2 of the following.

For group 1 and 2, the textbook is the primary English book 1A which published by Guandong education press [5]. During two month time, group 1 is taught 3 lessons for about 100 new words and 80 sentences. The reading amount is about 300 words. Group 2 is taught 8 lessons for about 200 new words and 200 sentences. The reading amount is about 700 words. The students spent 2 hours a week on weekend to attend the lessons. After the lesson, they are asked to go over the lessons that they have learnt on weekend. A network course based on an APP called superstar Xuexitong is opened to all the parents of the treatments. Most parents even recorded the reading process of their children. We can see that the parents have played a very important role in their children's learning.

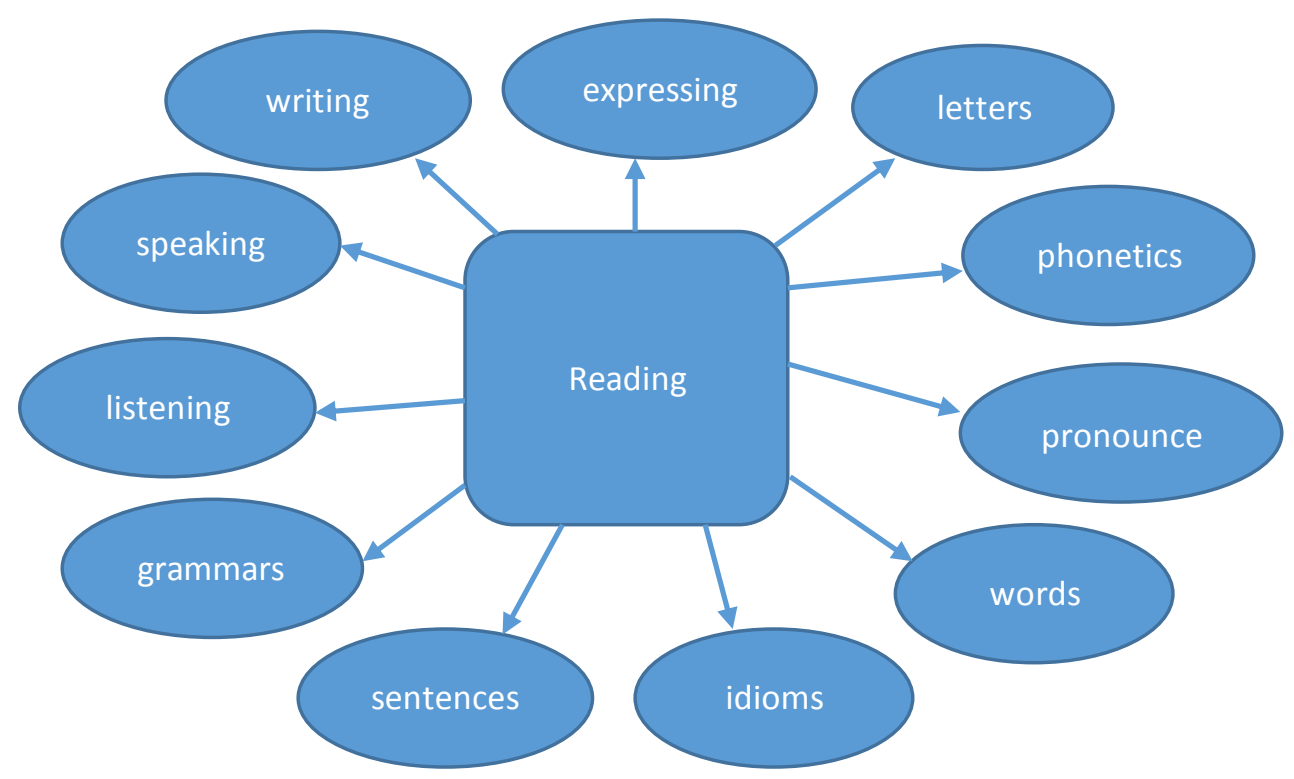

Figure 2. The principle of Integrated English teaching and learning

The post test results of these two experimental groups are as table 3 in the following. 
Table 3 The pretest of the experimental group

\begin{tabular}{|c|c|c|c|c|c|c|c|c|}
\hline Group & letters & phonetic & pronounce & $\begin{array}{c}\text { new } \\
\text { words }\end{array}$ & idioms & sentences & listening & speaking \\
\hline 1 & Yes & Yes & Yes & 124 & 5 & 42 & Yes & Yes \\
\hline 2 & Yes & Yes & Yes & 186 & 8 & 98 & Yes & Yes \\
\hline students & all & all & all & all & all & all & all & all \\
\hline
\end{tabular}

Reading is the primary learning way, so it is not listed in the table. Writing is not the primary item in this experiment. We adopt the naturally spelling and reading method to teach the treatments. According this method, the learner which can read the English sentences can also write the words. So they have got the ability of writing to some extent. Certainly, it is not the important aspect in this experiment.

Compare table 2 and table 3, we can see that the English learning effectiveness of the attendances all are very good. It illustrate that the community model of English learning is effective.

\section{Conclusions and Future Work}

In this paper, a primary English learning model based on learning community was proposed. In order to test the effectiveness, an experiment was designed. 20 primary students attend the experiment. All of them is the poor in English. After two months learning by using the Integrated English learning method, all students acquire the great progress in English learning. It illustrate that this model is effective. Certainly, because of the differences among the students, the learning quality is different from each other to some extent. Much more factors must be researched in the future study.

\section{References}

[1] Yu, H., Abrizah, A., \& Sani, M. K. J. A. 2016. Information literacy through resource-based learning: Malaysian teachers' conception and instructional practices. Malaysian Journal of Library \& Information Science, 21(2016), 53-67.

[2] Chun, D., Smith, B., \& Kern, R. 2016. Technology in language use, language teaching, and language learning. The Modern Language Journal, 100(S1), 64-80.

[3] So, W. W. M., \& Ching, F. N. Y. 2012. Online resource-based learning environment: Case studies in primary classrooms. Paper presented at the Asia-Pacific Forum On Science Learning And Teaching.

[4] International Cooperated Integrated English teaching and learning research center. http://www.integratedenglish.com/

[5] Primary Integrated English 1A, Guangzhou, Guangdong Education press. 2017

[6] Jane Medwell, David Wray, Hilary minns, Elizabath coates, Vivienne Griffiths. Primary school (teaching theory and practice). Fourth edition published by learning matters Ltd. in 2009. 